\title{
Factors Affecting the Acceptance of Game-based Learning
}

\author{
Nada Saleh, Edmond Prakash and Rob Manton \\ Institute of Research \& Applicable Computing \\ Department of Computing \\ University of Bedfordshire, UK
}

\begin{abstract}
Education is the process of teaching, educating and developing strategies of learning through developing skills, character and knowledge. Educational games and edutainment are educational methods introduced in educational systems to bring out the creativity and mentality of learners in the society. These technological learning systems engage the student to learn by full computer control through colorful animation and interactive learning methods. The aim is to develop the skills of the students technologically using shapes, visuals, multimedia, video, digital games etc, to try to draw out what is in the mind of the learners, thus improving their skills and ability to obtain more knowledge. Different researchers have expressed their views for and against the usefulness or relevance of educational games and edutainment in learning. Reported in this paper, is a survey of edutainment and educational games, their benefits, drawbacks and factors affecting the use of these technologies in education.
\end{abstract}

\section{INTRODUCTION}

Educational games are seen as chances to improve motivation and learning by presenting learners with autonomous, and open-ended learning. Because they allow learners to construct or discover the educational information by themselves, theorists theorize them to be a talented alternative to the currently used approach of paying attention to a teacher. Even though the advantageous influences of independent learning in educational games are sustained from a theoretical point of view, empirical research demonstrates both detrimental and beneficial influences on learning results. Despite the fact that a number of learners profit from learning in educational computer games, for further learners, particularly individuals with little previous knowledge, educational games have confirmed no more successful than conventional media. One of the possible intimidation not merely of educational computer games but of all problem-based, discovery-based, or empirical learning environments is that they create profound requirements on the working memory capacity of learners, by demanding redundant cognitive load that override the working memory limitation. In this case, learning will be reserved. Following cognitive load theory line, the whole cognitive load forced on the memory that is working throughout learning is additive, consisting of three kinds of loads: extraneous cognitive load, intrinsic germane cognitive load, and cognitive load [1].
Intrinsic cognitive load rely on the complex nature of the specified task concerning the level of expertise of learners. Extraneous cognitive load rely on the didactic intent of learning material; while, germane cognitive load is caused by the engagement of learners in the learning activity. Throughout education with games, an instance of extraneous and intrinsic aspects that excess the processing resources of learners is the complexity and amount of information that requires to be combined and processed with instantaneous events of motor and cognitive activities. Learners have to pay elevated attention on how to maneuver the game and manage empirical tasks during motor actions. Additionally, they must look for the tasks that possibly are postponed in time and space in the environment of game. These are frequently more complex than simply shooting, regulating, or experimental simulations chatting, and the accomplishment of the objective might include many or all of these. The tasks learning objectives are not clearly specified; however steadily clarify whereas learners interact with the game in order to achieve them. They must analyze and discover what the objectives of learning behind these missions are. They must illustrate presumptive conclusions from the outcomes of their efforts to resolve the mission, particularly when they have failed to achieve their objective and require repeating the attempt [1].

\section{EDUCATIONAL GAMES}

Electronic educational games are recreational and learning environments that attempt to enlarge the motivation of learners, by implanting educational activities in highly interesting interactions. In comparing the efficiency of games against conventional classroom instructions, it was specified that games were more efficient in the areas of mathematics, language and arts. The reason behind this is that in these domains, contents are more definite, and more efficient use of computers by learners indicated obvious benefits for the exercises above conventional teaching techniques. In addition, increased preservation was revealed in games, and students have interest in the activities more than the traditional classroom education. Nevertheless, there is modest experimental proof that electronic educational games have the ability to endorse learning if the communication is not led by instructors and integrated with other didactic activities. One probable reason for this restriction is that learning how to play does not essentially entail learning the area or the field [2].

Generally, games which are well designedas with fine planned education experiences are demanding but achievable. Games are sup- 
posed to provide players with challenges which are corresponding to their skill stage with the purpose of maximizing engagement. The level of complexity is put at the position where the learner has the ability to achieve the task with reasonable support, with guidance that will help to meet up with the next challenge. This stepwise complexity approach help players to shape strategies and knowledge that will be helpful to them in their educational process later. In a game, the failure price is lower. Students have the ability to take risks and rapidly learn from their mistakes. Efficient games present feedback that is unobtrusive, clear, and instantaneously receptive to the actions of the players. Moreover, the feedback helps in adding force to the students motivation, and students have the ability to become accustomed to the feedback, and the game continues to become accustomed with the student [3].

Designing and adapting game teaching and learning styles that are suitable to the students leads to a more active and energetic role in learning. For instance, students playing River City, which is a science inquiry game, had the ability to discover their learning environments separately, shaped their own hypotheses and managed their own experiments with the intention of solving the problem [4].

\subsection{Types of Educational Games}

As mentioned in authoring platforms or engines, students in this scenario utilize games to create an artifact, whether, it be a mod, a game, a video, a written text, a visual text, an avatar or a body of code. Evaluation forms that are used to evaluate these artifacts do not come from the games, but they come from the domain of design that is related to the artifact and what the artifact was created to express. Also, games are evaluated as dynamic systems with which students can check theories of how systems work and how certain principles of these systems can be monitored and played out. Offthe-shelf, commercial and web-based games can be utilized in the field of education to provide understanding about a specific subject or content area, in addition, virtual worlds or software platforms with games embedded can be utilized. For instance, students play Civilization game to learn about history or SimCity game to learn about urban planning. Also, students use Soda Play as a technique to test out physics-based theories and play Bridge Builder game to learn about bridges as systems of engineering. Often, simulations comprise their own internal assessment measures (data) that can be utilized in the evaluation of the understanding of students of both micro and macro elements. The field of education should provide students with opportunities to reflect on and discuss the content in the outer areas of the game in order to allow students to watch the game as part of a larger body of knowledge on a subject. Moreover, Games as context: trigger systems, is considered as one of the most important type where in these, games are utilized to produce an empirical context for understanding around an issue, principle, or topic that an instructor can develop. For instance, a math teacher may require students to play Dragons and Dungeons as an important way to enable them discover Pictionary or probability as a method to provide thoughts about communication forms. Students are provided with chances of discussion of and reflection on imported topics exterior to the game, in order to permit them to notice the game as division of a bigger body of knowledge on that topic. Based on the amount of time which is available, casual, nondigital, and commercial games can be utilized. The games are used as engines, and students are demanded to create a game as a good way to plunge themselves in the topic concerned with the research subject. Later experiences in learning are able to then build on what was taught so as to create a game [5].

Video and digital games are also considered one of the most important educational games and their design are focused on methods that will increase learners interest in education. The major feature that distinguishes video games and edutainment is reactivity, as the former is based on linear and didactical advancement, with no place for alternatives and wandering. Edutainment games follow a drill and skill arrangement in which players either repeat protected facts or perform repetitive skills. On the contrary, educational video games needs hypothesis, testing problem-solving, or strategizing frequently, not just simple comprehension or route memorization. The features of such games involve an order of goals and rewards which encourage players, a narrative context which situates motion and engagement rules, learning content that is related to the plot of narrative, and reactive cues that increase the process of learning and present feedback. None the less, even drill and skill games that utilize such features have confirmed positive increase in learning. It is found that a math facts game for second graders arranged on handheld computers, promoted learners to fulfill a larger number of problems at an amplified degree of complexity. Learners are utilizing the handheld game computers in order to increase their ability to learn easily in different areas such as science and math. Also, depending on these games, the level of complexity in learning decrease as they continued to play [6].

Another important element of the efficient video game design is the order of goals, objectives, and rules. Even though they are incorporated inside goals, rules, and a narrative context, and they are not inferior to context; they are significant elements of it. In an initiatives overview in educational games, the testing and design of three video game prototypes are described: Supercharged!, Environmental Detectives, an environmental science game and Revolution, a game for American history. Everyone has a narrative construction that students pursue in order to specify their goals or objectives. Players take the role of a charged element in the games, for instance, in Supercharged! Players take the role of a soldier, in Environmental Detectives, they take the role of scientists and in Revolution, they take the role of a townsperson or revolutionary. Every game has distinctive goals and a diversity of policies structure the play. Players have to overcome the rules of the game to achieve the objectives. For instance, the electromagnetism laws present the rules in Supercharged! [7].

The research of digital games has in the past six years become a lawful field of study, not basically study of the design and improvement of games, but of the educational potential of games, and significant acceptance as a cultural force in communities. Digital gaming presents rich immersive environments, using sophisticated and dazzling sounds and images, with textual communication, in order to produce practical worlds. Players have to read new and old aural, visual, and textual meanings, like an important element of a goodhumored engagement which is both challenging and pleasurable. The exponential profit growth in gaming is due to its capability to keep players engrossed in digital worlds, information, knowledge, and the development of skill, which turn out to be gradually more accessible outside the formal education and training confines. The problem of these cultural transferring is that they require a typical alteration of view to rethink and reshape the digital games study as an important information rich in cultural texts [8] 


\subsection{Barriers of using Educational Games}

The academic concern in focusing on the video games and computer educational potentiality has quickly amplified in the last few years. The orientation began with some influential works concerning the relation between the engagement and motivation presented by learning and games. From these works, a lot of authors have highlighted how games have the ability to make people of diverse circumstances concentrated and focused on a task throughout extended periods of time. Actually, additional studies about what create fun in learning have recognized features that are aligned with the principles of learning, favoring the skills improvement and competences more willingly than fact memorization [9].

One of the major barriers that prevent the espousal of educational games is the complexity which they present in the process of learning. Whereas a lecture does not need any investment in technology, videogames need a lot of equipments like computers, other digital devices and controlled environments. Schools frequently reduce this sort of tools. Additionally, even when these sorts of tools are provided in the schools, they frequently lack the team preparation and the time demanded to arrange the sessions for educational games. Correspondingly, the teachers resistance towards new technologies and the complexities of edutainment along with, once more, the lack of technological infrastructure are also considered as the major issues hindering the usage of game-based learning [10].

In order to tackle this issue, an efficient instrument to disseminate the games to the students would be to distribute them throughout a learning management system. Distributing a game throughout a learning management system is more efficient than other processes, resembling distributing CD ROMs to the students in class or configuration in the sessions school game. In addition, the assessment and tracking aspect of some modern learning management system would provide the teacher more power to manage the features of the learning experience, for instance when the students accessed the game, the time for every student spent playing it and the results of the game session. On the other hand, incorporating a game in a learning management system is still a compound task that requires particular knowledge from teachers [10].

\section{EDUTAINMENT}

Edutainment can be defined as a combination between entertainment and education, in a form of presentation or an action which uses multimedia such as a website or a television program [11]. Edutainment appeared in the late 1980s and the early 1990s and was produced to be an educational and entertainment tool. Edutainment industries became a thriving industry and enabled many companies to access and gain a market share in the industry, and give an effective learning tool for many children. In the late 1990s, edutainment software industries became weak and their sales decreased dramatically during the five years of decline [12]. After that, internet became the popular shape of edutainment. Various websites used edutainment as a method to attract visitors, but with time, edutainment became the main attraction method of these websites, which increased with the high distribution of personal computers throughout the world, Klopfer [5] stated that the combination between education and games are still moderate phenomena; also, most parents and teachers realize that using edutainment during classroom session can improve many skills for kids such as, planning, data analysis, negations skills and strategic planning, increase the concentration standards for children, and working within a team to participate in decision making. Also, promoting educa- tion using combinations of learning context and entertainment activities lead to increase in the passions and motivations of learners in different courses. There are edutainment software that utilizes various tools to encourage learning, like video games, music, programs on television, multimedia, films, and websites. Creative technology that uses tangible reaction in edutainment software enables learners to discover new things [13]. Designing the learning materials requires first studying the issues and the needs of the students while studying in the classrooms with the intention to achieve the educational goals. The second purpose is to make students feel pleasant when they play edutainment games. There are many kinds of edutainment like: television edutainment, internet edutainment, interactive television and computer edutainment [14].

Edutainment is known as a kind of education which integrates entertainment for educational purposes and uses video games for education as it is defined by the study in [15]. Edutainment can be used in daily life with concentration in mathematics, science and reading. There are edutainment software that uphold the cognitive skills for a child by utilizing pictures. Those edutainment software are easy to understand because they are intended for slow learners. Users can utilize edutainment applications depending on the content and the purpose of the edutainment software. First, they can improve the control in a users life (unofficial education) by using a narration or debate. Second, they give the kid an experiment inclusive education and skills that are usually applied by experienced simulation. For example, Figure 1 shows an application that uses a combination of colors, figures, and letters to enable kids to understand the subject. This application will be amusing when a child realizes the goal of this application from his/her perspective [15].

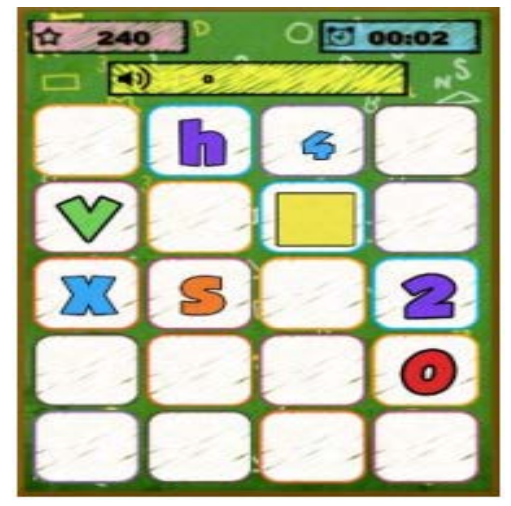

Fig. 1. Example of an edutainment game [15

Teaching by entertainment is an effective way to transform the complex issues to pleasant and attractive scenery [15]. Edutainment is defined as educational methods or activities that concentrate on learning through entertainment such as, teaching in simulated labs which have multiple fields of knowledge which generate innovative ideas.

Edutainment refers to utilizing computers for partly educational purpose with some entertainment within it. It is defined as a venue, which integrates education and entertainment and asks kids to enjoy what they learn. In addition to that, edutainment utilizes media elements like animation, texts, sounds, images and videos. Edutainment uses a mouse to select a fiction, photo, word and press while information still appear in the computer screen [16]. Edutainment is 
stated as a learning way that combines educational ingredients with entertainment to increase motivations, emotions and engagements [17].

Edutainment is also defined as a place where kids enjoy what they obtain of education with a mix of mediums (images, animations, sounds, texts and videos) by utilizing computers mouse to select a button, picture or word, all information and fictions will be kept on the screen. The purpose of edutainment environment is to apply new technology in education and be easy to use by learners [18]. Table 1 shows some examples of famous edutainment software such as Teletubbies, Bumba Laptop, Go Diego go, Computer Kid Friend, and Tweemies/Mega Knuetselfeest. The kind of each one of those games is represented in addition to the aims of every mini game. For example, the game Computer Kind Friend teaches children how to learn the letters, colors, numbers, and forms.

\subsection{Advantages of Edutainment}

The most attractive feature in Edutainment is its ability to raise motivations for its users; this feature is considered the most significant advantage of edutainment in education field, some teachers believe that motivations are the basic reason of utilizing edutainment games in classrooms but they believe that there are other features of edutainment besides motivation [11]. One of the edutainment tools is multimedia which enables students in schoolrooms to learn moderate matters, motivate and engage in the learning material [20].

Edutainment games have the advantage of student autonomy, but this is counted as a secondary feature of edutainment games [11]. Educational materials can be put on internet websites, thus, students can utilize edutainment software from home [21]. Edutainment provides students with interesting environments, where they can be motivated by sounds, photos, speech and lights to get knowledge. These motivators are used to enable students to resolve their problems independently [22].

The interesting design of the edutainment interfaces is also one of the most significant advantages of edutainment games along with motivation, this feature have wider and more long run influence in learning than motivation, because of that, it is considered as the primary reason to use computer games in education [11]. Another advantage gained from edutainment is in the tutors ability of selecting suitable materials before stimulating their students to use these materials. They are convenient to teach in foreign languages or to teach in schools [20].

Furthermore, there are other advantages of edutainment like alternative presentation; teachers are convinced that the most important feature of edutainment games is that it offers the educational materials in a new mode; this is an important point because students are stimulated and things are enjoyable [11]. Edutainment uses alternative ways in the educational process like learning by making a project, visual and audio learning and showing what a student did [20].Edutainment games enable learners to do more than recording notes or listening [21]. They help instructors to use creative tools instead of using traditional chalks and boards. Also, when teachers use these creative tools to teach learning materials, especially the ones for languages, students can learn these materials effectively.

Peer collaboration is considered as a feature of edutainment, it is also not as important as motivation based on many teachers attitudes; tutors believe that they can easily comprehend using edutainment within a conventional framework where there is concentration on the relationship between the software and the student [11]. Edu- tainment software grant many significant skills like collaboration of peers by enabling students to play together in a computer game that have little information. This enables them to adapt with changing environments, innovate and solve complex situations. Edutainment games give an opportunity for students to work in groups and to take part in doing learning activities; thus, collaboration skills will be improved [17].

\subsection{Disadvantages of Edutainment}

Despite the many advantages of edutainment, there are several disadvantages of applying edutainment games in the school environment.

Curriculum: Many edutainment games do not cover the standard curriculum. Teachers believe that edutainment software do not cover the educational content, there is a cultural comprehension that edutainment games do not match to educational content, and this problem appears mostly in computer games that were designed for only entertainment target. Additionally, there are trends which focus in designing computer games to fit with just a specific part of the curriculum to enable children to play and learn that portion, with motivational elements which they liked, thus superficially not covering all parts of the curriculum [11].

Content: Another challenge while creating edutainment content is how to balance between entertainment and education, by making games not very amusing or very exhausting for example: in several edutainment games, computer games and learning substances are so isolated that the player may pass a game without noting that there is an educational content within it. In addition to that, imperfect building and incoherence of the content and shortage of educational pattern are often stated as problems of digital educational substance [14].

Technical Expertise: Teachers face huge technical barriers because they think that they will have problems regarding the learning of modern hardware and their maintenance matters [11]. Another problem that arises while applying edutainment games in education is the shortage of professional expertise who do not have enough knowledge to deal with external resources of edutainment games. A high expertise is needed to transform from traditional educational methods to edutainment method; for example, educator needs to plan what he/she wants to present during the semester, then he/she has to translate the views and the knowledge to a programmer who transforms them into a game formula. Edutainment games must be applied correctly because if the instructor implements the edutainment software incorrectly, it will be distracting rather than beneficial [21]. All foreign and local computer games need some parameters for assessment, particularly finished produced games that are not cognitively suitable for kids who are five to six years, educators have to reproduce edutainment methods again to adjust with learning requirements, noting that reproducing them entails high technical knowledge [21].

Cost: Expenses are considered as one of the most down-to-earth obstacle, and these costs may be an obstacle for applying these technologies in schools [11]. Making video games require millions of dollars and many years to complete them where as books costs much less than that to acquire [21]. 
Table 1.

Some

edu-

tain-

ment

games

with

their

kinds

and

claims

[19]

\begin{tabular}{|c|c|c|c|c|}
\hline Game Name & Publisher & Kind of game & Advised Age & Educational claims \\
\hline Computer Kid Friend & Clementoni & Mini-laptop & From 3 years & $\begin{array}{l}\text { Learning letters, numbers, forms and } \\
\text { colours }\end{array}$ \\
\hline Bumba Laptop & VTech & Mini-laptop & From 9 months & $\begin{array}{l}\text { Learning forms, objects, words, sounds and } \\
\text { music, language development, sensory de- } \\
\text { velopment, discovering and exploring, mo- } \\
\text { tor skills }\end{array}$ \\
\hline Teletubbies (1998) & $\begin{array}{l}\text { BBC Worldwide Ltd. } \\
\text { Memphis Belle B.V. }\end{array}$ & Cd-Rom & From 2 years & $\begin{array}{l}\text { Learning areas: eye-hand coordination, } \\
\text { talking and listening, recognizing forms, } \\
\text { places, sizes, amounts, spatial insights, fol- } \\
\text { lowing patterns, fantasy and creativity }\end{array}$ \\
\hline $\begin{array}{l}\text { Tweenies Mega Knut- } \\
\text { selfeest (2004) }\end{array}$ & $\begin{array}{l}\text { BBC Worldwide Ltd. } \\
\text { Memphis Belle B.V. }\end{array}$ & Cd-Rom & From 3 years & Creativity and fantasy \\
\hline $\begin{array}{l}\text { Go Diego go! (Nick jr) } \\
\text { (2008) }\end{array}$ & $\begin{array}{l}\text { Viacom International } \\
\text { Inc. }\end{array}$ & Cd-Rom & From 3 years & $\begin{array}{l}\text { Learning new animals, animal sounds and } \\
\text { tracks, development of visual and motor } \\
\text { skills, solving problems, counting, respect- } \\
\text { ing animals and environment }\end{array}$ \\
\hline
\end{tabular}

\subsection{Factors Influencing the Acceptance of Edutainment}

There are several factors effecting the acceptance of edutainment for both students and teachers. Researchers did multiple studies about these factors which are mentioned below, and there are various perspectives about the influence of these factors on edutainment. The following sub-sections represent some of those factors which affect the edutainment.

3.3.0.1 Usability. Usability is defined as the degree of learnability of the game. Children deal simply and intuitively with the games and most users do not face problems related to playing games and do not receive instructions from observations. According to Hussain [16], usability is also known as the keys or human agents, which is called human computer interface, recently combined with playability of a user, and defined as the operational ability of a user to proceed in a specific mission. According to Embi [18] usability is a significant agent when designing educational software. It is the volume in which a product can be utilized by particular users for special targets with achieving satisfaction, efficiency, and effectiveness in limited field of usage. Usability can be applied in educational field with concentration in designing of learning actions, user interface and assuring if learning aims are achieved. The interface in educational software must be intuitive; educational software is to make the children work in a learning environment which is performed by games. There is positive relationship between usability and likeability; if the game is more usable then it is more likeable [23]. Edutainment software raises the flexibility in the relations among the users, designers, developers, and increases the reusability of the resources [24]. Usability in educational field creates the educational actions, and examines if the learning targets are achieved, and the usability of the requirements have to be existed for usable interface, which also must be intuitive and do not distract the kids to accomplish the fixed targets. There is also a conventional mode that evaluates performance, detects the troubles that users face when they utilize the interface, then the users are asked their options about the product, but it is significant to take care when collecting the data about the children.

3.3.0.2 Ease of use. The flexible environment of edutainment games give the users the ability to repeat tests in an experiment with ease, supply feedback to increase the performance, the simultaneous control, and the diagrammatic representations [25]. There are some advantages of edutainment which are; interactivity, renewal, ease of divide, flexibility in space and time, and the ease of utilizing. There is an easy usage of edutainment; for example, web interface is popular for many people at organizations and homes [26]. Edutainment games improve the cognitive ability of a kid by utilizing photos which are amazing and easy to understand and use [15]. Tests of edutainment could be experimented with using almost all senses, and it is comprehended by students regardless if they are applied in classes or as homework [27]. The users must be trained about using edutainment applications to appear as a funny and easy technology. Edutainment games give users whom are children and older people a very soft instrument which enables them to comprehend the complex concepts of development of a dynamic body within an interesting learning environment [28]. When kids utilize edutainment games, they learn through entertainment, kids who like education will interact and learn with edutainment soft- 
ware, thus edutainment games enable them to feel motivated with learning and to see things softly, because of that, they can put in additional efforts without displeasure. The software gives the children a chance to explore new things and to search more details about them. Users generally found that edutainment games are easy to use by utilizing a mouse with computer interface and manipulating realistic pasteboard photos. Kids like learning, easiness of the usage and fun, and because of that, edutainment games are the best tool to educate children [15]. In edutainment games, all the contents of the software are presented with the regular and coherent interactive property, they also provide navigation property that enables learners to move easily from one module to another. Children are attracted to the multimedia of educational content because they have dynamics, colorful, and beautiful parts. Edutainment games give an opportunity for students to play in an environment that is like reality, they enable them to react easily and naturally with the objects in the games, students can link the related learning substances with these objects in an amusing mode [29].

\subsubsection{Usefulness. There is a major benefit of edutainment} that is obvious in technological applications in various fields of knowledge. The benefit of edutainment technology is to make children happy and motivated; it uses cognitive methods, contrasting the alternatives of the solution, producing examples, and meaningful results of new experience [30]. Edutainment games have benefits in learning, it motivates people to participate in local courses, or make them as tutors, build a learning group in their area, and request needed resources from the local government and other organizations and utilizes them in educational activities [31]. Edutainment games combine entertainment and education that is convenient for tutors and they are easy in usage. Also, edutainment applications can be manipulated in pedagogical environments [16]. Edutainment games grant skills for children like the ability to manage complicated missions, conclude task in time and adapt fast to changeable environments. When players perceive a relationship between games' substances and their daily life they will take part actively in the educational operations, users also pay attention to edutainment games if they are submitted as a quiz or challenge [32]. Edutainment games lower the costs of development and give rich experience which is intuitive for the users; the educational content are presented in games [24]. There is an important improvement in education when children use edutainment software. There are many benefits of edutainment games. For example, it supplies motivation, problem solving, involvement, fun, structure, story, interactivity and reaction [33]. In formal education, computer games are considered as a learning mode, they give important skills to students like critical thinking, problem solving and independent learning, noting that teachers are responsible for implementation of computer games in schoolrooms. Edutainment games are beneficial to students and instructors; edutainment games save effort and time for instructors, students can be motivated and gain high skills like creative thinking, evaluation skill, analytical skill, perception and judgments [34]. Learners perceive games as real environment and link the information and knowledge that they learned to their daily life, regardless of the students competency levels and the learning mode, the software enables the children to take part and motivate actively [29].Edutainment games are significant tools to gain knowledge and they have long term effects on the learning process. They can be used to teach a specific material and they improve many students skills like creative thinking, handling data skills, negotiation skill, problem solving, working within a team, math skills, decision making and planning [29].
3.3.0.4 Effectiveness. Dependence level of students in edutainment activities and events is low, which has a positive effect on effectiveness. When users utilize cognitive ways, the independent thinking skill of learners will be developed. Some researchers and instructors try to replace conventional learning methods with edutainment games, but there are no documented outcomes yet. Edutainment games do not always achieve the estimated targets because there are multiple factors which influence the success of edutainment game in accomplishing their goals. These factors are that they must be conveniently challenging, substantially motivating, and have elements of fantasy, curiosity, and control. Edutainment games do not have an advantage on traditional learning mode unless they make students remember what they learn, alter users perspectives and keep students interests. Edutainment games are the best tool to improve the skills of students who have low academic performance and low language level [35]. Edutainment games stimulate children slowly to learn and discover new things about fields of knowledge [36]. Television programs that present entertainment and effective educational content can be considered as edutainment and there is advancement in the enjoyment and effectiveness of the users when they play edutainment games [37]. Online edutainment software has formative evaluations that enable learners to assess their comprehension of the educational content, this way increases the students attention of learning and raises their grades, and feedback is very significant to pedagogical process [38]. Edutainment games have a positive effect on learning outcomes especially in mathematics materials, which are realized expeditiously by students as supplying interesting multimedia, thus edutainment software helps in achieving educational targets [33]. Producers and designers of the games must be critical to the teachers requirements, this will increase teachers interest in applying edutainment in classrooms and enhance the learning environment [34]. Edutainment software is an effective instrument when delivering the values meant by associated stories. Students stated that using multimedia in edutainment is an effective way to learn new vocabularies in a specific language and to ease the comprehension of a given story. Edutainment games are effective instruments that help teachers to teach complex subjects in the educational curricula. Effective edutainment software has multiple properties like learning by doing, authenticity and collaboration. Edutainment games focus on implementing of the known knowledge rather than getting completely new subject. Edutainment games are the effective instruments to teach children writing skills, by making students work together, making a draft; then, modifying the written essay, and finally, writing the final mission to complete a specific one [29].

3.3.0.5 Architecture. There are ingredients that assist in adjusting the educational content with the cognitive level of the students and professors plans. The narrative part in edutainment is a significant part because it pays attention to various serial events. Architecture permits a child to act his/her preferred characters in RPG (Role-Playing Game), these ingredients react with realistic world patterns, and they manage the domain pattern of the game and spread of multimedia. There is a challenging mission to make a balance between how to teach and what to teach, the type of game has to be selected seriously so that learning motions become more effective [39].According to study in Sobral [19], the efficiency of narrative pattern, usability, reaction facilities and character design are significant for evaluation of the architecture. And this technology (edutainment) has a utility for educational content, Sobral [19] stated that the directives of edutainment software have to match with cognitive architecture of people and human differences. The moderate design of the games generates more complicated archi- 
tecture systems, and new demands related to required infrastructure regarding human resources and substances to create and apply it in schools; for example, last versions of exchange-card game are suitable for children who are 5-14 years old, whereas new versions of the same game concentrate on users who are 15 -35 years old [40].

3.3.0.6 Cognitive Artifact. Hussain [16]declared that cognitive artifact must be included in computer games like mathematics to permit a child to express his/her beliefs about mathematics. There are things that must be considered in mind about the artifact of edutainment. These are: efficient teaching, efficient learning, efficient communication of the material and effectively utilizing the technology to accomplish them. Edutainment software must be created actively by enabling the user to do something, not only to watch it. When the learner interacts with multimedia, he/she will involve in the game actively, thus the attention of the learner will be increased. It has a positive influence on learning mode and customization of pace to fit the special demands of the learner [41]. The user can involve and manipulate the artifacts, then he/she builds his/her perception about specific themes, the user involves in micro world and builds connections and items that are combined in virtual artifacts. Designing games, creating the knowledge, and playing with the items in various modes by children are appeared these days [11].

3.3.0.7 Enjoyment. Enjoyment is considered as the most suitable measurement of stimulation because enjoyment assesses how a game assists in completing the mission that is related to the targets. Learning must be associated with enjoyment, thus the concepts will stay on in children memories [16]. Boys are incredibly affected by enjoyment rather than girls when they play edutainment games. The standard of learning retention, enjoyment, and the satisfaction of user-interface rises in edutainment. Edutainment games give many benefits for learning like passions of curiosity, power, fantasy, enjoyment, and fear [42].

3.3.0.8 Storytelling. Storytelling is a significant area where kids can improve their skills, interpretation, recall, expression, communication, analysis and recognition. Storytelling enables kids to use their voices, implement their language, expand their imagination and improve on their narrative skills [17].Digital storytelling means that using the digital media to create immersive and wealthy stories, it is intended to achieve two targets: First, it upholds the learning experiments of the users by making the games stories fits with users preferences, enabling the user to discover in educational environments, and enabling the user to react actively with the playing game and the narrative pattern. Second, adaptive and reactive storytelling works in redesigning of usability of learning content by making various stories appear more real, the completely different games which is based on less or more of the same elements like patterns, structure, atomic story units and the concepts of the games and learning.

3.3.0.9 Interactivity. A lot of children feel happy when they react with mathematics along with soft input instruments and when they play games [18]. In creating interactive edutainment; designing games by learners is a new pattern which focuses in creating a reactive educational content that upholds the user when he/she works in new activities and learns from moderate themes. In computer edutainment for the kids, utilizing the characters for the fun intent is the common way in applying amusing contents [14]. Interactivity is an element that influences on edutainment with a positive effect in improvement of learning; it can raise the ability of children to discover new things. It concentrates on curiosity of the children then it makes the children pay attention for a long time constantly. The discovery can enhance problem solving skills for the children; by using trial and error mode to learn, their knowledge will be improved. A child learns by efficient control of edutainment applications, all these components of edutainment exist in computer games. Because these games involve fun, they satisfy the emotional and psychological necessities of the children. The computing skill, which is produced by creative games, enhances the educational context that is based on advantages of interactivity [43].

\subsection{Students' Attitudes Towards Edutainment}

There are different attitudes of students towards utilizing edutainment games in education. Many students have negative views about edutainment games, they believed that edutainment games lack of instructions, standards, learning aims, and content makes it impossible to count these games as strong learning environment. However, many users are satisfied with edutainment games in terms of the interface, sounds, reaction and attractive colors that stimulate involvement and interesting learning for students. There is another positive property, which is the feedback of edutainment games, which gives them important skills and help learners accomplish the required tasks [19]. There is another perspective from students and teachers about applying edutainment games in schoolrooms and these are problems related to edutainment games quality and effectiveness; the instructors do not know the way in which to teach the edutainment games, and students also do not also know how to study [44]. Many students consider edutainment games as effective tools for teaching because multimedia reaction modes can be adapted to create suitable learning substances with entertaining shapes, users desire for pleasure and favorable expertise, this pleasure results from entertainment, interesting educational content, and problem solving skill that edutainment games build in the users [37]. Teachers in traditional methods face challenges when they teach the curriculum; these educational materials are not engaging and students need to be motivated constantly to be involved in these materials, but when teachers utilize edutainment games, students concentration increase. Edutainment methods in education create game atmosphere and reactive learning to enable students to engage in these materials [38]. Many teachers think that edutainment games in education have disadvantages such as the fact that many teachers have little experience about computer games and do not make a change when edutainment applications are applied, but other teachers are convinced that edutainment games have advantages; for example, edutainment games raise the students motivation [11].

\subsection{Gamification}

Gamification is defined as using games parts in none-games fields to stimulate and raise awareness of activity in amusement media, finance, education, sustainability, productivity, and news. Gamification is defined in educational field as an important and serious implementation of thinking games to stimulate users to resolve various problems and assist in learning, and it utilizes all the suitable ingredients of the games, it focuses on how particular positions or processes of video games can cheer and transform individuals, groups and institutions. Gamification concentrates on using the techniques, principles, and tools of the games to circulate them to various contexts of education, and enables the students, who feel that certain educational materials are hard to comprehend, to be engaged in these educational materials. For example, there are two games which are Orangetree game for common libraries 
and Lemontree game that is used in academic libraries. Huddersfield university in united kingdom applies Gamification; Lemontree game focuses on the management of data system of the library, its about the customers who come to play the game, then they win presents if they deserve it. There are many ways to take part in this game; when players visit the library frequently, they get points to utilize e-resource which enable them to open new achievements with the names of achievements owners and their achievements published in Facebook to highlight on the features of the library.

\section{CONCLUSSION}

Edutainment games are known as integration between amusement and education using various multimedia. and improve many skills for children such as, strategic planning, analytical skills, working within a team and decision making. Edutainment games give users important skills like working within a team, creativity, the ability to explore, and interactivity. Edutainment games make users stimulated and involved in interesting learning environment, and enable students to transfer the complicated matters to simple matters that is easy to understand and attractive.

Interactivity is the main variance between edutainment games and educational games. Educational games are liner educational advancement; they do not give choices for students, but edutainment games apply "skill and drill" form which gives an opportunity for students to apply what skills and information they have. Educational games have different sides like abstract and concrete, and enable students to work independently and discover new things. There are many factors that affect or influence edutainment games: usability is an example of these factors and is defined as the extent in which a product can be used for specific aims and by a particular user. Ease of use is another factor, and it means that there are flexible environments in the games, thus users can put their plans and repeat the examinations of an experiment in particular period with ease of using them. Usefulness is a feature of edutainment games; there are management benefits of edutainment games that they can be applied in various fields of knowledge, virtual reality gives a chance for students to try interesting edutainment environments, they also give important skills for students like adapting fast with changing positions and management of hard tasks. Effectiveness is an advantage of edutainment games; they motivate students to explore new things, increase students' attention towards educational materials and raise their grades. There are other factors of edutainment games like cognitive artifact, architecture, enjoyment, storyteller, interactivity etc.

Edutainment games are known as integration between amusement and education using various multimedia and improve many skills for children such as, strategic planning, analytical skills, working within a team and decision making. Edutainment games give users important skills like working within a team, creativity, the ability to explore, and interactivity. Edutainment games make users stimulated and involved in interesting learning environment, and enable students to transfer the complicated matters to simple matters that is easy to understand and attractive. Interactivity is the main variance between edutainment games and educational games. Educational games are linear educational advancement; they do not give choices for students, but edutainment games apply skill and drill form which gives an opportunity for students to apply what skills and information they have. Educational games have different sides like abstract and concrete, and enable students to work independently and discover new things. There are many factors that affect or influence edutainment games: usability is an example of these factors and is defined as the extent in which a product can be used for specific aims and by a particular user. Ease of use is another factor, and it means that there are flexible environments in the games, thus users can put their plans and repeat the examinations of an experiment in particular period with ease of using them. Usefulness is a feature of edutainment games; there are management benefits of edutainment games that can be applied in various fields of knowledge, virtual reality gives a chance for students to try interesting edutainment environments, they also give important skills for students like adapting fast with changing positions and management of hard tasks. Effectiveness is an advantage of edutainment games; they motivate students to explore new things, increase students attention towards educational materials and raise their grades. There are other factors of edutainment games like cognitive artifact, architecture, enjoyment, storyteller, interactivity, etc. Edutainment games have many advantages: they raise the motivation of students, give students independence and flexibility, increases learners interests in subjects, encourages peer collaborations and gives learners important skills such as creativity and adapting to changing situations. There are some disadvantages of edutainment games such as: edutainment software does not include all aspects of educational contents, many teachers think that these games do not match the curriculum because they are designed for entertainment aim. There are tendency to create edutainment games to suit particular section in the educational content. Technical barriers are one of the edutainment games obstacles; learning new software of edutainment and their servicing is an obstacle for instructors. There is a problem related to lack of teachers who can deal effectively with the external resources of edutainment software, it requires teachers to give the conventional learning materials to expert programmer to transfer these materials to a game formula, instructors must implement edutainment games correctly. Costs are considered as the largest barrier faced in implementation of edutainment games in classrooms, they require quality people to create them and long time to complete these games. Culture is another obstacle and many instructors think that edutainment games are an effective way in educational domain, but their culture prevents them to exploit this technology in education because they believe that these games will isolate learners from childhood activities.

\section{REFERENCES}

[1] C. Schrader and T. Bastiaens, "Learning in educational computer games for novices: The impact of support provision types on virtual presence, cognitive load, and learning outcomes." International Review of Research in Open \& Distance Learning, vol. 13, no. 3, 2012.

[2] C. Carmona and D. Bueno, "From mito to samo: Evolution of an educational game for spanish orthography," Journal of Computers, vol. 2, no. 4, pp. 9-16, 2007.

[3] K. L. McClarty, A. Orr, P. M. Frey, R. P. Dolan, V. Vassileva, and A. McVay, "A literature review of gaming in education," Gaming In Education, 2012.

[4] H. A. Spires, J. P. Rowe, B. W. Mott, and J. C. Lester, "Problem solving and game-based learning: Effects of middle grade students' hypothesis testing strategies on learning outcomes," Journal of Educational Computing Research, vol. 44, no. 4, pp. 453-472, 2011.

[5] E. Klopfer, S. Osterweil, K. Salen et al., "Moving learning games forward," 2009. 
[6] M. J. Dondlinger, "Educational video game design: A review of the literature," Journal of Applied Educational Technology, vol. 4, no. 1, pp. 21-31, 2007.

[7] J. P. Gee, "Why are video games good for learning," Unpublished manuscript. Retrieved, vol. 23, 2007.

[8] S. De Castell, J. Jenson, and N. Taylor, "Digital games for education: When meanings play," Intermedialities, vol. 9, pp. 45-54, 2007.

[9] J. P. Gee, "Good video games and good learning: Collected essays on video games, learning and literacy (new literacies and digital epistemologies)," 2007.

[10] J. Torrente, P. Moreno-Ger, I. Martínez-Ortiz, and B. Fernandez-Manjon, "Integration and deployment of educational games in e-learning environments: The learning object model meets educational gaming." Journal of Educational Technology \& Society, vol. 12, no. 4, 2009.

[11] S. Egenfeldt-Nielsen, Beyond edutainment: Exploring the educational potential of computer games. IT University of Copenhagen, Department of Innovation, 2005.

[12] C. Shuler, "What in the world happened to carmen sandiego?" in The edutainment era: Debunking myths and sharing lessons learned. New York, NY: The Joan Ganz Cooney Center at Sesame Workshop, 2012.

[13] K. Sorathia and R. Servidio, "Learning and experience: Teaching tangible interaction \& edutainment," ProcediaSocial and Behavioral Sciences, vol. 64, pp. 265-274, 2012.

[14] S. Walldén and A. Soronen, "Edutainment," 2004.

[15] S. Wirawan, F. F. Muhammad, L. D. Saifudin, M. Ibrahim et al., "Analysis of child computer interaction in edutainment and simulation games application on android platform in indonesia." International Journal of Advanced Computer Science \& Applications, vol. 4, no. 7, 2013.

[16] H. Hussain, Z. C. Embi, and S. Hashim, "A conceptualized framework for edutainment," Informing Science: InSiteWhere Parallels Intersect, pp. 1077-1083, 2003.

[17] F. Garzotto and M. Forfori, "Fate2: storytelling edutainment experiences in $2 \mathrm{~d}$ and $3 \mathrm{~d}$ collaborative spaces," in Proceedings of the 2006 conference on Interaction design and children. ACM, 2006, pp. 113-116.

[18] Z. C. Embi and H. Hussain, "Theoretical framework for edutainment: the cognitive engineering," in Proceedings of the 6th WSEAS International Conference on Multimedia, Internet \& Video Technologies, 2006.

[19] D. Sobral, I. Machado, and A. Paiva, "Machiavellian characters and the edutainment paradox," in Intelligent Virtual Agents. Springer, 2003, pp. 333-340.

[20] C. Galina and K. Olena, "Edutainment and foreign languages teaching," 2007.

[21] N. Pennola, "Education through video games," 2009.

[22] T. Pasawano, "Development of an edutainment for learning support of bachelor degree," International Journal of Wireless Information Networks \& Business Information System, vol. 5, pp. 45-50, 2012.

[23] M. Virvou and G. Katsionis, "On the usability and likeability of virtual reality games for education: The case of vr-engage," Computers \& Education, vol. 50, no. 1, pp. 154-178, 2008.

[24] I. Deliyannis, A. Giannakoulopoulos, and I. Varlamis, "Utilising an educational framework for the development of edutainment scenarios," 5th European Conference on Game Based Learning (ECGBL 2011), 2011.
[25] Y. Kara and S. Yesilyurt, "Assessing the effects of tutorial and edutainment software programs on students achievements, misconceptions and attitudes towards biology," in Asia-Pacific Forum on Science learning and teaching, vol. 8, no. 2. Hong Kong Institute of Education. 10 Lo Ping Road, Tai Po, New Territories, Hong Kong, 2007, pp. 83-96.

[26] V. Lonesco, "Staff edutainment on corporate internet-lessons learned," 1998.

[27] O. Miglino, O. Gigliotta, M. Schembri, and D. A. Ferdinando, "Collective adaptive agents as techniques to build-up edutainments systems," 2009.

[28] D. Wagner, D. Schmalstieg, and M. Billinghurst, "Handheld ar for collaborative edutainment," in Advances in Artificial Reality and Tele-Existence. Springer, 2006, pp. 85-96.

[29] M. A. Raheem and A. Ashraf, "The effect of using computer edutainment on developing 2nd primary graders' writing skills." Online Submission, 2011.

[30] Z. Okan, "Edutainment: is learning at risk?" British Journal of Educational Technology, vol. 34, no. 3, pp. 255-264, 2003.

[31] P. Devlin, "Edutainment: the benefits of arts and crafts in adult and community learning," 2008.

[32] M. S. Khine and M. S. B. Sujaee, "Core attributes of interactive computer games and adaptive use for edutainment," in Transactions on edutainment I. Springer, 2008, pp. 191-205.

[33] S. P. Hwa, "Create an edutainment learning environment for mathematics learning in primary schools," in Proceeding of 2nd International Conference on Teaching and Learning (ICTL 2009): Achieving Educational Excellence through Student Centred ApproachISBN, pp. 978-983.

[34] J. Shih Chi Tang and C. C. Fung, "Edutainment content management requirements from teachers' perspectives," 2007.

[35] J. G. Hogle, "Considering games as cognitive tools: In search of effective" edutainment."." 1996.

[36] T. Braun and K. Berns, "Edutainment with climbing roboticsa practical course for students," 2007.

[37] D. Rigas and K. Ayad, "Guidelines for edutainment in elearning systems." 2011.

[38] S. Bakke, R. H. Faley, and G. Steinberg, "How effective is student-centric edutainment in large introductory is survey courses?" 2008.

[39] G. Huesca, J. Noguez, L. Neri, and V. Robledo-Rella, "Work in progressusing interactivity video games factors to define role playing games as a supporting tool for learning by doing," in Frontiers in Education Conference (FIE), 2010 IEEE. IEEE, 2010, pp. T1E-1.

[40] A. Artusi, M. Joly-Parvex, G. Lucet, A. Ribes, D. Pitzalis et al., "Plug, université paris nuit: A design reiteration of a mobile museum edutainment application,” 2010.

[41] K. Jegers and C. Wiberg, "Funtain: Design implications for edutainment games," in proceedings of World Conference on Educational Multimedia, Hypermedia and Telecommunications (Ed-Media), Chesapeake, VA, AACE, 2003.

[42] M. R. Stone, "Edutainment: Gaming and simulation an educational tool," 2008.

[43] S.-K. Tzeng and C.-F. Huang, "A study on the interactive" hopscotch" game for the children using computer music techniques." International Journal of Multimedia \& Its Applications, vol. 2, no. 2, 2010. 
[44] L. Huiyang and R. Jianfeng, "Review of edutainment and flash in the field of educational," International Journal of Information and Education Technology, no. 5, pp. 340-344, 2011. 